\title{
Large Outbreak of Jimsonweed (Datura stramonium) Poisoning due to Consumption of Contaminated Humanitarian Relief Food: Uganda, March-April 2019
}

\section{Ronald R. Mutebi ( $\square$ mutebi2r@musph.ac.ug )}

Uganda Public Health Fellowship Program, Ministry of Health

\section{Alex R. Ario}

Uganda Public Health Fellowship Program, Ministry of Health

Maureen Nabatanzi

Uganda Public Health Fellowship Program, Ministry of Health Irene B. Kyamwine

Uganda Public Health Fellowship Program, Ministry of Health

\section{Yvette Wibabara}

Uganda Public Health Fellowship Program, Ministry of Health

\section{Peter Muwereza}

Uganda Public Health Fellowship Program, Ministry of Health

\section{Daniel Eurien}

Uganda Public Health Fellowship Program, Ministry of Health

\section{Benon Kwesiga}

Uganda Public Health Fellowship Program, Ministry of Health

\section{Lilian Bulage}

Uganda Public Health Fellowship Program, Ministry of Health

\section{Steven N. Kabwama}

Uganda Public Health Fellowship Program, Ministry of Health

\section{Daniel Kadobera}

Uganda Public Health Fellowship Program, Ministry of Health

\section{Alden Henderson}

Division of Global Health Protection, Center for Global Health, US Centers for Disease Control and Prevention

\section{John H. Callahan}

Center for Food Safety and Applied Nutrition, Food and Drug Administration

Timothy R. Croley

Center for Food Safety and Applied Nutrition, Food and Drug Administration

Ann M. Knolhoff 
Center for Food Safety and Applied Nutrition, Food and Drug Administration

John B. Mangrum

Center for Food Safety and Applied Nutrition, Food and Drug Administration

Sara M. Handy

Center for Food Safety and Applied Nutrition, Food and Drug Administration

\section{Melinda A. McFarland}

Center for Food Safety and Applied Nutrition, Food and Drug Administration

\section{Jennifer L. Fong Sam}

Center for Food Safety and Applied Nutrition, Food and Drug Administration

\section{Julie R. Harris}

Division of Global Health Protection, Center for Global Health, US Centers for Disease Control and Prevention

\section{Bao-Ping Zhu}

Division of Global Health Protection, Center for Global Health, US Centers for Disease Control and Prevention

\section{Research Article}

Keywords: Jimsonweed, Food poisoning, Outbreak, Humanitarian, Uganda

Posted Date: March 10th, 2021

DOI: https://doi.org/10.21203/rs.3.rs-198802/v1

License: (c) (1) This work is licensed under a Creative Commons Attribution 4.0 International License. Read Full License

Version of Record: A version of this preprint was published at BMC Public Health on March 30th, 2022. See the published version at https://doi.org/10.1186/s12889-022-12854-1. 


\section{Abstract}

\section{Background}

Jimsonweed (Datura stramonium) contains toxic alkaloids that cause gastrointestinal and central nervous system symptoms when ingested. This can be lethal at high doses. The plant may grow together with leguminous crops, mixing with them during harvesting. Due to persistent famine in Uganda's Karamoja region, area residents receive humanitarian food relief. On 13 March 2019, more than 200 casepatients were admitted to multiple health centres for acute gastrointestinal and neurologic symptoms. We investigated to determine the cause and magnitude of the outbreak and recommend evidence-based control and prevention measures.

Methods

We defined a suspected case as sudden onset of confusion, dizziness, convulsions, hallucinations, diarrhoea, or vomiting with no other medically plausible explanations in a resident of Napak or Amudat District from 1 March - 30 April 2019. We reviewed medical records and canvassed all villages of the 8 affected sub-counties to identify cases. In a retrospective cohort study conducted in 17 villages that reported the earliest cases, we interviewed 211 residents about dietary history during 11-15 March. We used modified Poisson regression to assess suspected food exposures. Food samples underwent chemical (heavy metals, chemical contaminants, and toxins), proteomic, DNA, and microbiological testing in one national and three international laboratories.

Results

We identified 293 suspected cases; five (1.7\%) died. Symptoms included confusion (62\%), dizziness (38\%), diarrhoea (22\%), nausea/vomiting (18\%), convulsions (12\%), and hallucinations $(8 \%)$. The outbreak started on 12 March, 2-12 hours after Batch X of fortified corn-soy blend (CSB+) was distributed. In the retrospective cohort study, $66 \%$ of 134 persons who ate CSB+, compared with $2.2 \%$ of 75 who did not, developed illness $\left(R_{\mathrm{adj}}=22,95 \% \mathrm{Cl}=6.0-81\right)$. Samples of Batch $\mathrm{X}$ distributed 11-15 March contained 14 tropane alkaloids, including atropine (25-50ppm) and scopolamine (1-10ppm). Proteins of Solanaceae seeds and Jimsonweed DNA were identified. No other significant laboratory findings were observed.

Conclusion

This was the largest documented outbreak caused by contamination of food with tropane alkaloids. Implicated food was immediately recalled. Routine food safety and quality checks could prevent future outbreaks.

\section{Background}


The jimsonweed (Datura stramonium) is a plant in the Solanaceae or nightshade family. All parts of the plant contain tropane alkaloids, including atropine (D, L-hyoscyamine), hyoscyamine (levsin), and scopolamine (L-hyoscine). If ingested, the anticholinergic properties of tropane alkaloids in the plant can affect the central and peripheral nervous system. Severe poisoning may manifest with hallucinations, delirium, agitation, seizures, hyperthermia, and rhabdomyolysis [1, 2], as well as death at higher doses[3]. Jimsonweed often grows in the same fields as agricultural crops such as soybeans, linseed, and wheat, and can contaminate crops during harvest [4]. The alkaloids are relatively heat-stable, and after harvesting, processing and food preparation, the toxins can still cause poisoning if ingested [4].

Tropane alkaloids from plant sources have caused food poisoning outbreaks in the past, including outbreaks from contaminated flour [5], alkaloid-containing berries [6], and other foods contaminated by alkaloid-containing plant parts [7]. Contamination of food usually occurs when toxic plant parts are accidentally mixed with edible plants during harvest or processing $[5,8]$.

On 13 March 2019, the health offices of Amudat and Napak Districts notified the Uganda Ministry of Health of an outbreak involving more than 200 persons in the two districts. Patients' symptoms included fever, headache, confusion, convulsion, and abdominal discomfort; some patients were reportedly experiencing severe disease. We investigated the outbreak to determine the nature of the illness, the scope and cause of the outbreak, and recommended evidence-based control and prevention measures.

\section{Methods}

\section{Outbreak area}

The outbreak occurred in Napak (population: 155,500) and Amudat (population: 129,400) districts located in the Karamoja region, Northeastern Uganda [9)]. The Karamoja Region borders Kenya to the east and South Sudan to the north. The region suffers from chronic food insecurity. According to the United Nations Children's Fund (UNICEF), 46\% of the households in the region are considered foodinsecure and 9\% were severely food-insecure in 2017 [10]. Karamoja is a semi-arid area, where most of the population subsists through pastoral livelihoods. The majority of residents need food assistance from humanitarian support. Since 2009, a maternal and child health nutrition program of the World Food Program (WFP) has been distributing super corn soy blend (CSB+) [11], vegetable oil, and sugar to pregnant and lactating women and children aged 6-23 months in a bid to reduce chronic malnutrition. In addition, a community-based supplementary feeding program distributes super-corn soy blend plus (CSB++), Plumpy'Nut ${ }^{\circledR}$, sugar, and cooking oil to pregnant and lactating women and children aged 6-59 months to treat moderately acute malnutrition (MAM) [12].

\section{Case definition and finding}

We defined a suspected case as sudden onset of any central nervous system (CNS) symptoms (i.e., hallucination, unusual/aggressive behavior, confusion, dizziness, distorted vision, convulsion, disorientation, and loss of consciousness) or gastrointestinal symptoms (i.e., diarrhea and 
nausea/vomiting) with no other medically plausible explanations in a resident of Amudat or Napak District from 1 March to 30 April 2019. We reviewed health facility records in the affected areas and conducted active case-finding in the affected villages with support of community health workers and health workers who had prior knowledge of the affected villages ("Manyattas"). We developed a line list for identified suspected cases.

\section{Descriptive epidemiology and hypothesis generation}

To generate hypotheses about the potential exposures that caused this outbreak, we analyzed the line-list data to characterize case-persons by their clinical presentations (signs and symptoms), personal characteristics (age and sex), symptom onset time (epidemic curve), and place of residence (village and district). We randomly sampled 15 case-patients from the line list and interviewed them using a structured questionnaire about their history of potential exposures (history of receiving and eating relief food, eating other foods, drinking unsafe water, and attending social gatherings).

\section{Retrospective cohort study}

Our initial investigation showed that in households with cases, almost all family members had eaten at least one form of relief food between 11 and 15 March 2019, suggesting the relief food might be implicated. To test this hypothesis, we conducted a retrospective cohort study in all 17 villages of the two most affected sub-counties in Napak District. We targeted all households that received relief food and interviewed all household members. We administered a standardized questionnaire focusing on the key exposures that emerged during the hypothesis generation process. We interviewed 211 respondents in these households. We obtained information on any clinical symptoms, demographic characteristics (age, sex, education), and exposures (receiving relief food and eating CSB+, CSB++, cooking oil, sugar, and other local foods). Since the attack rate was higher than $5 \%$, we used modified Poisson regression [13] to evaluate the exposures and to reduce the effects of confounding. We analyzed the data using Stata ${ }^{\text {TM }} 14$.

\section{Laboratory and autopsy investigations}

We obtained two CSB + flour samples from households of case-persons and one CSB + flour sample from the home of a non-case-person in the affected villages. We also obtained two CSB + samples from villages without cases as controls. These samples were shipped to three international laboratories for investigation: Intertek in South Africa, Mérieux Nutrisciences Laboratories in Italy and the Center for Food Safety and Applied Nutrition at the Food and Drug Administration (CFSAN/FDA) in United States. We provide a detailed methodology used by CFSAN/FDA because they conducted a deeper analysis of the food samples.

CFSAN/FDA analyzed the samples for metals by inductively coupled plasma mass spectrometry (ICPMS) using FDA Method EAM 4.7[14], and for chemicals and toxins by liquid chromatography high resolution tandem mass spectrometry (LC-HRMS/MS) and gas chromatography mass spectrometry (GCMS) $[14,15]$. Atropine and scopolamine were identified by LC-HRMS/MS (Shimadzu Nexera liquid chromatograph with a Kinetex C18 column coupled to a Thermo Q-Exactive mass spectrometer). 
Compound identity was confirmed by accurate mass measurement, isotope ratio fit, molecular formula match and MS/MS spectrum match to a compound database, as well as retention time matching to standards [15]. Compound identities were also confirmed by GC/MS (Agilent 7890B/5975C gas chromatograph mass spectrometer) $[15,16]$. Spectra were confirmed with the NIST Mass Spectral Library and matching retention time and mass to atropine and scopolamine standards. Atropine and scopolamine were quantified using LC-HRMS using calibration curves generated from atropine and scopolamine standards. Protein identification was conducted by nanoscale liquid chromatography tandem mass spectrometry (nano-LC/MS/MS). Samples digested with trypsin were injected into a Waters NanoAcquity chromatograph (Symmetry C18 Trap Column, C18 BEH reverse phase column) coupled to a Thermo Scientific Orbitrap Lumos Tribrid mass spectrometer and peptide fragmentation data was searched against custom protein databases using the Mascot (Matrix Science) search algorithm and protein parsimony software to identify seeds from the Solanaceae family as a contaminant [17]. Shotgun metagenomic DNA analysis (genome skimming) was performed to identify the sources of the toxins. DNA was extracted with a Qiagen DNeasy mericon Food Kit using the standard protocol, pooled, and then uniformly sheared with a Covaris-focused ultrasonicator. Libraries were prepared using a Kapa Biosciences Hyper prep kit and sequenced using whole genome shotgun sequencing (also called genome skimming) approach on an Illumina Miseq using a V3 600 cycle kit. Samples were also sent to the Mérieux Nutrisciences Laboratories in Italy to be analyzed on behalf of the WFP for similar analysis, and to Intertek in South Africa for microbiological and toxicological analysis.

The Uganda Police authorized autopsies be done on the bodies of three of the deceased.

\section{Trace-back investigations}

We conducted a trace-back investigation to identify the source of the implicated food. We also conducted interviews with WFP and health facility staff regarding the source, storage, and distribution of the relief food.

\section{Results}

\section{Descriptive epidemiology}

We identified 293 suspected cases, including 215 in Napak (attack rate [AR] = 14/10,000) and 78 in Amudat $(A R=6.1 / 10,000)$. The overall AR in the two districts was 10/10,000. Of the 293 case-patients, 5 died (case-fatality rate [CFR] $=1.7 \%$ ), including 4 in Napak (CFR $=1.9 \%$ ) and 1 in Amudat (CFR $=1.3 \%$ ). Two deceased persons were children (ages 2 and 10 years).

The most common symptoms among case-patients involved the central nervous system (Table 1). Some case-patients presented with gastrointestinal symptoms. Notably, $21 \%$ of patients reported fever and both jaundice and bleeding were absent. For most case-persons, symptoms resolved within 24 hours after treatment with intravenous fluids, activated charcoal, and sedatives. No antibiotics were given. Females 
$(A R=12 / 10,000)$ were significantly more affected than males $(A R=9 / 10,000 ; p=0.006)$. Persons aged less than 5 years were most affected $(A R=13 / 10,000)$.

Lotome sub-county $(A R=120 / 10,000)$ in Napak district and Karita sub-county $(A R=14 / 10,000)$ in Amudat district were the most affected (Figs. 1a and 1b).

Table 1

Distribution of symptoms among 91 case-patients with food poisoning: Napak and Amudat districts, March-April 2019

\begin{tabular}{|c|c|c|}
\hline Signs and symptoms & Number of Case Patients & Percentages $(n=91)$ \\
\hline \multicolumn{3}{|l|}{ Central Nervous System } \\
\hline Confusion & 56 & 62 \\
\hline Dizziness & 35 & 38 \\
\hline Headache & 29 & 32 \\
\hline Uncoordinated speech & 27 & 30 \\
\hline Distorted vision & 19 & 21 \\
\hline Convulsion & 11 & 12 \\
\hline Hallucinations & 7 & 8 \\
\hline Loss of consciousness & 5 & 6 \\
\hline \multicolumn{3}{|l|}{ Gastrointestinal System } \\
\hline Abdominal pain & 26 & 29 \\
\hline Diarrheal & 20 & 22 \\
\hline Nausea/Vomiting & 16 & 18 \\
\hline Jaundice & 0 & 0 \\
\hline \multicolumn{3}{|l|}{ Others } \\
\hline Fever & 19 & 21 \\
\hline Dry throat & 9 & 10 \\
\hline Tachycardia & 5 & 5 \\
\hline Bleeding & 0 & 0 \\
\hline
\end{tabular}

Cases were clustered around health facilities that distributed the relief food (Figure 2). 
In both Amudat and Napak districts, symptom onsets started on 12 March 2019, shortly after Batch X of CSB + was distributed on 11 March 2019. The outbreak subsided after CSB + was recalled from the community. However, some members of the community did not return the CSB + despite intensive and extensive efforts by the WFP to recall the food. In late-March and mid-April, two smaller outbreaks occurred after the community members started to eat the CSB + that they did not return to the WFP (Fig. 3).

\section{Hypothesis generation findings}

All 15 case-patients who participated in the hypothesis-generating interviews reported that they had eaten relief food supplied by WFP, particularly CSB+, during 11-15 March 2019; 14 (95\%) had also eaten other indigenous foods such as greens, millet, and ground nuts during the same period. No common sources were identified for the indigenous foods eaten. Three case-patients (20\%) reportedly used an unsafe water source; none had attended any public gathering at which food was served.

Based on the findings from descriptive epidemiology and hypothesis-generating interviews, we hypothesized that eating relief foods, particularly CSB+, distributed in Napak and Amudat districts during 11-15 March 2019 was associated with the outbreak.

\section{Retrospective cohort study findings}

Eating CSB + was associated with illness $(R R=26)($ Table 2). Two other food items distributed with CSB + in the same time period were also significantly associated with illness; sugar ( $R R=2.7)$ and cooking oil $(R R=2.5)$. However, after controlling for confounding using the modified Poisson regression model, eating CSB + was the only significant exposure $\left(R_{\mathrm{adj}}=22\right)($ Table 2$)$. 
Table 2

Association between foods eaten and disease status among 211 respondents during a food poisoning outbreak: Napak and Amudat districts, Uganda, March-April 2019

\begin{tabular}{|c|c|c|c|c|c|c|}
\hline Foods* & Ate & $\begin{array}{l}\text { Total } \\
\text { Respondents }\end{array}$ & $\begin{array}{l}\text { Respondents } \\
\text { ill }\end{array}$ & $\begin{array}{l}\text { Attack rate } \\
\text { (\%) }\end{array}$ & RR (95\% Cl) & $\begin{array}{l}\mathrm{RR}_{\mathrm{adj}}(95 \% \\
\mathrm{Cl}) \dagger\end{array}$ \\
\hline \multirow[t]{2}{*}{ CSB+ } & Yes & 134 & 89 & 66 & $26(6.5-101)$ & $22(6.0-81)$ \\
\hline & No & 77 & 2 & 2.6 & reference & \\
\hline \multirow[t]{2}{*}{ CSB++ } & Yes & 8 & 1 & 13 & $\begin{array}{l}0.28(0.045- \\
1.8)\end{array}$ & $1.4(0.13-14)$ \\
\hline & No & 203 & 90 & 44 & reference & \\
\hline \multirow[t]{2}{*}{ Sugar } & Yes & 67 & 51 & 76 & $2.7(2.1-3.7)$ & $\begin{array}{l}1.3(0.96- \\
1.8)\end{array}$ \\
\hline & No & 144 & 40 & 28 & reference & \\
\hline \multirow[t]{2}{*}{$\begin{array}{l}\text { Cooking } \\
\text { oil }\end{array}$} & Yes & 52 & 41 & 79 & $2.5(1.9-3.3)$ & $\begin{array}{l}1.1(0.87- \\
1.5)\end{array}$ \\
\hline & No & 159 & 50 & 31 & reference & \\
\hline \multirow[t]{2}{*}{$\begin{array}{l}\text { Other } \\
\text { foods }\end{array}$} & Yes & 208 & 90 & 43 & $\begin{array}{l}1.3(0.26- \\
6.5)\end{array}$ & $2.3(0.49-11)$ \\
\hline & No & 3 & 1 & 33 & reference & \\
\hline
\end{tabular}

\section{Laboratory, toxicology, and autopsy findings}

Of the three laboratories that analyzed the samples, two (CFSAN/FDA and Mérieux Nutrisciences Laboratories) produced concordant results; the third (Intertek) did not conduct alkaloids testing.

Initial laboratory analysis of one of the samples for microbiological and heavy metal contamination did not reveal unusual levels of bacteria, yeast, or heavy metals (Table 3). Results from untargeted liquid chromatography high resolution mass spectrometry showed high levels of the tropane alkaloids, including atropine, scopolamine, anisodamine, aposcopolamine, and apoatropine (Table 4). 
Table 3

Levels of various contaminants detected in the implicated batch of CSB + during a food poisoning outbreak: Napak and Amudat districts, Uganda, March 2019

\begin{tabular}{|c|c|c|}
\hline Agent(units) & Average & Allowable(Max) \\
\hline \multicolumn{3}{|l|}{ Microbiological(Counts) } \\
\hline Mesophilic Aerobic Bacteria & 400 & 100000 \\
\hline Coliform & $<10$ & 100 \\
\hline Salmonella & ND & 0 \\
\hline E-Coli & ND & 10 \\
\hline Staph aureus & $<10$ & 10 \\
\hline Bacillus Cereus & $<10$ & 50 \\
\hline Yeast/Mould & 50 & 1000 \\
\hline \multicolumn{3}{|l|}{ Mycotoxins } \\
\hline Ochratoxin(ppb) & $<1$ & 50 \\
\hline Aflatoxins B1(ppb) & ND & 5 \\
\hline Total Aflatoxins(ppb) & ND & 20 \\
\hline Fumonison(ppm) & $<0.1$ & 2 \\
\hline \multicolumn{3}{|l|}{ Heavy Metals(ppm) } \\
\hline Lead & ND & 0.02 \\
\hline Cadmium & 0.02 & 2 \\
\hline Mercury & ND & 0.1 \\
\hline Arsenic & ND & 0.2 \\
\hline Copper & 3.5 & 30 \\
\hline \multicolumn{3}{|l|}{ Premix(mg/kg) } \\
\hline Iron & 9.8 & 14.1 \\
\hline Zinc & 6.5 & 8.3 \\
\hline \multicolumn{3}{|l|}{ Pestcides } \\
\hline Organochlorine & ND & 0 \\
\hline Organophosphorus & ND & 0 \\
\hline Pyrethoids & ND & 0 \\
\hline
\end{tabular}




\section{Agent(units) Average Allowable(Max)}

ND: Not Detectable; ppm: parts per million; ppb: parts per billion

Table 4

Levels of alkaloids detected from corn-soy blend plus (CSB+) in affected and non-affected households during a food poisoning outbreak: Napak and Amudat districts, Uganda, March 2019

\begin{tabular}{|lll|}
\hline \multicolumn{3}{|c|}{ Alkaloids level (ppb) } \\
\hline Sample & Atropine & Scopolamine \\
\hline From affected households & \\
\hline B & 28,633 & 3,621 \\
C & 54,574 & 7,457 \\
E & 26,818 & 2,803 \\
From unaffected households & & \\
A & 883 & 112 \\
\hline D & Non-Detectable & Non-detectable \\
\hline
\end{tabular}

Protein identification by LC MS/MS resulted in the identification of 1740 proteins, $92 \%$ of which were related to corn and soy. There were 139 proteins attributed to the Solanaceae family and most shared some sequence homology with related corn and soy proteins. However, 13 protein groups (22 proteins) were exclusive to Solanaceae and shared no homology with corn or soy. Fifteen seed storage proteins were identified in samples that had been identified as having relatively high levels of atropine and scopolamine. The existing protein databases did not contain enough entries from across Solanaceae to allow protein analysis to indicate a specific plant species. However, the correlation between toxins and seed storage proteins from Solanaceae family (i.e., nightshade, belladonna, and jimsonweed), aligned with concurrent DNA analysis. Shotgun metagenomic DNA analysis (genome skimming) of samples identified quantities of Datura stramonium (jimsonweed) DNA that roughly correlated with atropine/scopolamine levels in some, but not all, samples.

Autopsies conducted on three of the five decedents showed no visual evidence of infection or internal organ damage that could explain the death.

\section{Traceback investigation findings}

Before February 2019, WFP had distributed Batch W of CSB+ ('old stock') to health facilities in the region. This Batch was distributed to beneficiaries and subsequently eaten with no reported problems. In March 
2019, Batches $X$ and $Y$ ('new stock') were supplied to health facilities that had little or no old stock of Batch W CSB + left. Another Batch, Z, was supplied to two refugee camps in the country (Fig. 4). The two affected districts had received Batch $X$ during 11-14 March 2019. Two contracted companies were involved in transporting Batch $\mathrm{X}$ from a central distribution point in Tororo, Uganda to an extended distribution point in Moroto, where the food was further distributed to the health facilities. Batch X was imported into Uganda from Mombasa, Kenya. Records show that this batch came from Turkey. We were unable to further identify the precise location in Turkey where the CSB + was produced or how it was processed.

\section{Discussion}

Our investigation revealed an outbreak of tropane alkaloid poisoning. The identification of atropine and scopolamine in a ratio of roughly 10:1 suggested a potential botanical source for the contamination; Jimsonweed (Datura stramonium) was identified as a contaminant of corn-soy-based humanitarian relief food distributed to the affected population. The outbreak occurred in a food-insecure region in northeastern Uganda where relief food has been distributed for many years. This was the largest such outbreak ever recorded in the published literature [4].

Symptoms reported by patients during this outbreak, particularly neurologic symptoms, were consistent with other studies of tropane alkaloid poisoning $[2,5,17,18]$. Consistent with other food poisoning incidents involving tropane alkaloids $[19,20]$, many patients, especially children, developed aggressive behavior resulting in skin injuries such as bruises and cuts. Symptoms started within 2 hours of eating $\mathrm{CSB}+$ food, which is consistent with poisoning; fever among some case-patients was consistent with the pharmacokinetic effects of atropine following quick absorption from the gastrointestinal tract [21]. The absence of jaundice and bleeding made aflatoxicosis unlikely as an etiology [22].

This outbreak caused five deaths. Previous outbreaks of unintentional tropane alkaloid poisoning have rarely resulted in death $[5,19,23]$. The deaths in this outbreak are likely associated with the high concentrations of tropane alkaloids in the implicated batch of CSB+. Levels of atropine and scopolamine in this outbreaks were hundreds of times higher than ones reported in other cases of domestic food poisoning and the allowable levels set by the European Food Safety Authority [4, 24]. As with all toxins, tropane alkaloid toxicity is dose dependent. The toxic doses for individual tropane alkaloids have been previously estimated based upon human case reports. In adult humans, more than $10 \mathrm{mg}$ of atropine is expected to cause significant toxicity, whereas more than $50 \mathrm{mg}$, or $1-2 \mathrm{mg} / \mathrm{kg}$, may be fatal. Data for scopolamine toxicity is scarce; however, doses of $78-435 \mathrm{mg}$ have been reported to cause significant toxicity in adults, and as little as $10 \mathrm{mg}$ may be fatal in children [25]. The high number of deaths could also be due to the presence of multiple tropane alkaloids in Batch X, coupled with the high prevalence of malnutrition among children aged 6-59 years (stunting $45 \%$ and underweight at $31.9 \%$ ) in the Karamoja Region [26]. 
The contaminated corn-soy relief food in our study was sourced from Turkey. Jimsonweed, which favors growth in fields of leguminous crops, has long been known to exist in Turkey [27]. Contamination of soy with toxic weed seeds, including jimsonweed, has long been recognized [28]. Physically, jimsonweed seeds are similar to some varieties of soy seeds in color and size, making it possibly difficult to separate the two during processing [29]. Identification of proteins from Solanaceae seeds and isolation of DNA of jimsonweed in Batch $\mathrm{X}$ suggested the possibility of contamination at harvesting and production stages due to failure of quality control mechanisms along the value chain [30]. This has also been the commonest route of contamination by tropane alkaloids in previous incidents of unintended food poisoning $[5,19,23]$. The finding that 'control' CSB + samples sourced from un-affected households and central warehouse also contained low levels of atropine $(<50 \mathrm{ppb})$ indicates that low-level atropine contamination could be widespread [31].

During this investigation, tracking Batch $\mathrm{X}$ back to the point of manufacture proved difficult as batch numbers were related to donation consignment and not related to date of production, source of raw materials or machine plant. This is contradictory to documented best practices [32-34]. Furthermore, packaging of CSB + lacked unique serial numbering that could have aided sequential tracking of the individual food sacks distributed. All these factors made it difficult to establish possible points of contamination along the supply chain beyond production stage. Labeling such shipments in the future should maintain a coding system that enables tracking back to the source of the product, to enable efficient trace back. Lotome and Karita sub-counties were the most affected of the 12 sub-counties evaluated. Health facilities serving these sub-counties were the first ones to run out of Batch W and began distributing Batch $\mathrm{X}$, the implicated food; this also accounts for the clustering of cases around these health facilities. The reasons for the higher attack rates among females over five years of age was likely due to differences in gender roles in this community; males spend most of their time away from home in dry seasons, searching for greener pastures to feed their cattle, while women primarily stay at home [35].

Our investigation had three major strengths. First, we conducted a rigorous and thorough epidemiologic investigation, closely following the standard steps of an outbreak investigation [36]. Second, the FDA/CFSAN of United States and Mérieux Nutrisciences Laboratories in Italy, both world-renowned laboratories, conducted independent testing of the food samples, and the results corroborated with each other. Third, the clinical presentations of patients were consistent with both the identified chemical agent (tropane alkaloids) and the plant source (Datura stramonium). However, we were unable to confirm the etiologic agent in human samples, and due to logistical limitations, we were unable to trace the food to its origin to determine exactly how the corn and soy were contaminated with jimsonweed. This trace-back investigation would have aided in the identification of the source and mechanism of contamination.

\section{Conclusion}

This outbreak was caused by consumption of food contaminated with tropane alkaloids from jimsonweed seeds. This is the largest such outbreak documented to date. 


\section{Public Health Actions}

Immediately after the outbreak was detected and the initial investigation was conducted, the Ministry of Health of Uganda instructed health facilities to stop the distribution of all WFP food, and advised households to stop the consumption and immediately return all WFP food to health facilities where the food was issued. The WFP dispatched teams to visit the communities to proactively stop distribution of food from health facilities, and to collect the already-distributed food from households. Following these actions, cases ceased except for a few small clusters that occurred among some residents that failed to return the food. After the outbreak was over, thinking it was now safe to eat the food, they began eating the retained Batch $X$ food. After the investigation provided strong epidemiologic and laboratory evidence to implicate Batch X of CSB+, WFP completely sealed off (embargoed/removed) the implicated food but resumed supply of the non-implicated food to the region. Enhanced surveillance in the community did not identify any new cases beyond April 2019.

\section{Abbreviations}

AR: Attack Rates; CDC: Centers for Disease Control and Prevention; CDP: Central Distribution Point; CFR: Case Fatality Rate; CHW: Community Health Workers; Cl: Confidence Interval; CNS: Central Nervous System; CSB+: Corn Soy Blend Plus, DNA: Deoxyribonucleic acid; GC: Gas Chromatography; MAMA: Moderate Acute Malnutrition; MS: Mass Spectrometry; PPB: Parts per Billion; PPM: Parts Per Million; UBOS: Uganda Bureau of Statistics; UNICEF: United Nations Children's Funds; WFP: World Food Program.

\section{Declarations}

\section{Ethical considerations}

Because this investigation was in response to a public health emergency, we did not seek for ethical approval from an institutional ethics review committee. However, Ministry of Health gave the directive to investigate this outbreak. In agreement with the International Guidelines for Ethical Review of Epidemiological Studies by the Council for International Organizations of Medical Sciences (1991), the Office of the Associate Director for Science, CDC/Uganda (Center for Global Health Human Subject Research-CGH HSR tracking number; 2019-104), determined that this activity was not human subjects research and its primary intent was public health practice or a disease control activity (specifically, epidemic or endemic disease control activity).

Verbal informed consent was obtained from the participants before the start of each interview. Given the emergency nature of the investigation and the illiteracy nature of the community, we did not obtain written informed consent. However, the purpose and nature of the investigation were explained to all participants. Participants were also informed that their involvement was entirely voluntary and their refusal to answer any or all of the questions would not result in any negative consequences. Participants identified as patients were referred for free treatment at the designated treatment centres. To protect 
participants' confidentiality, personal information was de-identified during data analysis, and the interview forms were locked up.

\section{Consent for Publication}

Not applicable.

\section{Regulations}

All methods were carried out in accordance with relevant guidelines and regulations.

\section{Availability of data and materials}

The datasets upon which our findings are based belong to the Uganda Public Health Fellowship Program. For confidentiality reasons the datasets are not publicly available. However, the data sets can be availed upon reasonable request from the corresponding author and with permission from the Uganda Public Health Fellowship Program.

\section{Competing interests}

The authors declare that they have no competing interests.

\section{Funding and Disclaimer}

This project was supported by the President's Emergency Plan for AIDS Relief (PEPFAR) through the US Centers for Disease Control and Prevention Cooperative Agreement number GH001353-01 through Makerere University School of Public Health to the Uganda Public Health Fellowship Program, MoH. Its contents are solely the responsibility of the authors and do not necessarily represent the official views of the US Centers for Disease Control and Prevention, the Department of Health and Human Services, Makerere University School of Public Health, or the $\mathrm{MoH}$. The staff of the funding body provided technical guidance in the design of the study, ethical clearance and collection, analysis, and interpretation of data and in writing the manuscript.

\section{Authors' contributions}

RRM: Participated in the conception, design, analysis, and interpretation of the study, and wrote the first draft of manuscript; MN, IK, YW, PM and DE reviewed the report, reviewed the drafts of the manuscript for intellectual content, and made multiple edits to the initial drafts of the manuscript; SNK, BK, LB, DKJC, AH, JHC, TRC, AMK, ARA, JH, BPZ, MAM reviewed the manuscript to ensure intellectual content and scientific integrity. All authors read and approved the final manuscript.

\section{Acknowledgement}

We thank the Uganda Public Health Fellowship Programme staff for the technical guidance and support during the study. Special recognition goes to the Ministry of Health, Uganda for trusting us with this 
responsibility. We also thank the staff of the United States Food and Drug Administration Center for Food and Applied Nutrition (CFSAN) laboratories and Mérieux Nutrisciences Laboratories for their comprehensive work towards analysis of food samples. Finally, we thank the WFP, Napak and Amudat District Health Offices for the support they availed to the response team while in the field as well as for providing information on the response measures implemented in the district.

\section{References}

1. Forrester, M.B., Jimsonweed (Datura stramonium) exposures in Texas, 1998-2004. Journal of Toxicology and Environmental Health, Part A, 2006. 69(19): p. 1757-1762.

2. Blackford, Assessment of serum creatine kinase among adolescent patients following jimsonweed (Datura stramonium) and moonflower (Datura inoxia) ingestions: a review of 11 cases. Clinical Toxicology, 2010. 48(5): p. 431-434.

3. Soni, P., et al., Pharmacological properties of Datura stramonium L. as a potential medicinal tree: an overview. Asian Pacific journal of tropical biomedicine, 2012. 2(12): p. 1002-1008.

4. Adamse, P., et al., Tropane alkaloids in food: poisoning incidents. Quality Assurance and Safety of Crops \& Foods, 2014. 6(1): p. 15-24.

5. Perharič, L., et al., Risk assessment of buckwheat flour contaminated by thorn-apple (Datura stramonium L.) alkaloids: a case study from Slovenia. Food Additives \& Contaminants: Part A, 2013. 30(2): p. 321-330.

6. Southgate, Unseasonal severe poisoning of two adults by deadly nightshade(Atropa belladonna). Journal of the Royal Society of Health, 2000. 120(2): p. 127-30.

7. Lazzarini, Food poisoning by Datura stramonium: an unusual case report. Internal and emergency medicine, 2006. 1(1): p. 88-90.

8. $\mathrm{Ng}$, Simultaneous detection of 22 toxic plant alkaloids (aconitum alkaloids, solanaceous tropane alkaloids, sophora alkaloids, strychnos alkaloids and colchicine) in human urine and herbal samples using liquid chromatography-tandem mass spectrometry. Journal of Chromatography B, 2013. 942 : p. 63-69.

9. Uganda Bureau of Statistics population projections, Population Projections, 2015-2020. 2019.

10. UNICEF, Food Security and Nutrition Assessment in Karamoja Sub-Region, June 2017. 2017.

11. UNICEF, Food Security and Nutrition Assessement Karamoja Sub-region_ Uganda June 2014

12. WFP, World Food Program Standard Project Report in Uganda. 2017.

13. Zou, G., A modified poisson regression approach to prospective studies with binary data. American journal of epidemiology, 2004. 159(7): p. 702-706.

14. FDA, U.S., Elemental Analysis Manual (EAM) for Food and Related Products. 2018.

15. Knolhoff, A.M., C.N. Kneapler, and T.R. Croley, Optimized chemical coverage and data quality for nontargeted screening applications using liquid chromatography/high-resolution mass spectrometry. Analytica chimica acta, 2019. 1066: p. 93-101. 
16. Papoutsis, I., et al., A simple and sensitive GC/MS method for the determination of atropine during therapy of anticholinesterase poisoning in serum samples. Drug testing and analysis, 2012. 4(3-4): p. 229-234.

17. Le Garff, E., et al., Forensic features of a fatal Datura poisoning case during a robbery. Forensic science international, 2016. 261: p. e17-e21.

18. Lounasmaa, M. and T. Tamminen, The tropane alkaloids, in The alkaloids: chemistry and pharmacology. 1993, Elsevier. p. 1-114.

19. Rwiza, H., Jimson weed food poisoning. An epidemic at Usangi rural government hospital. Tropical and geographical medicine, 1991. 43(1-2): p. 85-90.

20. Krenzelok, E.P., Aspects of Datura poisoning and treatment. Clinical Toxicology, 2010. 48(2): p. 104110.

21. Gilman, A., J. Hardman, and L. Limbird, Goodman and Gilman's, the Pharmacological basis of erapeutics. 2001, McGraw-Hill, New York, NY, USA.

22. de Oliveira, C.A. and C.H. Corassin, Aflatoxins. 2014, Future Medicine.

23. Beyer, J., O.H. Drummer, and H.H. Maurer, Analysis of toxic alkaloids in body samples. Forensic science international, 2009. 185(1-3): p. 1-9.

24. Authority, E.F.S., D. Arcella, and A. Altieri, Human acute exposure assessment to tropane alkaloids. EFSA Journal, 2018. 16(2): p. e05160.

25. Drummer, O.H., Randall C. Baselt, Disposition of Toxic Drugs and Chemicals in Man, Biomedical Publications, Seal Beach, CA. 2015, Elsevier.

26. Taremwa, J. and F. Ahabyoona, Malnutrition among children under-five in Uganda: burden, causes and prospects in Karamoja Region. International Journal of Technology and Management, 2018. 3(1): p. 12-12.

27. Tutin, T.G., et al., Flora Europaea. Vol. 3, Diapensiaceae to Myoporaceae. 1972: Cambridge UP.

28. List, G., G. Spencer, and W.H. Hunt, Toxic weed seed contaminants in soybean processing. Journal of the American Oil Chemists' Society, 1979. 56(8): p. 706-710.

29. Henry, W.T. and T.T. Bauman, Interference between soybean (Glycine max) and jimsonweed (Datura stramonium) in Indiana. Weed Technology, 1991. 5(4): p. 759-764.

30. Ponte, S. and P. Gibbon, Quality standards, conventions and the governance of global value chains. Economy and society, 2005. 34(1): p. 1-31.

31. Cirlini, M., et al., Are tropane alkaloids present in organic foods? Detection of scopolamine and atropine in organic buckwheat (Fagopyron esculentum L.) products by UHPLC-MS/MS. Food chemistry, 2018. 239: p. 141-147.

32. Zhang, J. and T. Bhatt, $A$ guidance document on the best practices in food traceability. Comprehensive Reviews in Food Science and Food Safety, 2014. 13(5): p. 1074-1103.

33. Crandall, P.G., et al., Whole-chain traceability, is it possible to trace your hamburger to a particular steer, a US perspective. Meat science, 2013. 95(2): p. 137-144. 
34. Golan, E.H., et al., Traceability in the US food supply: economic theory and industry studies. 2004.

35. Opondo, M., U. Abdi, and P. Nangiro, Assessing gender in resilience programming: Uganda. Kampala: BRACED Resilience Intel, 2016.

36. Papagiotas, S.S., et al., From SARS to 2009 H1N1 influenza: the evolution of a public health incident management system at CDC. Public Health Reports, 2012. 127(3): p. 267-274.

\section{Figures}

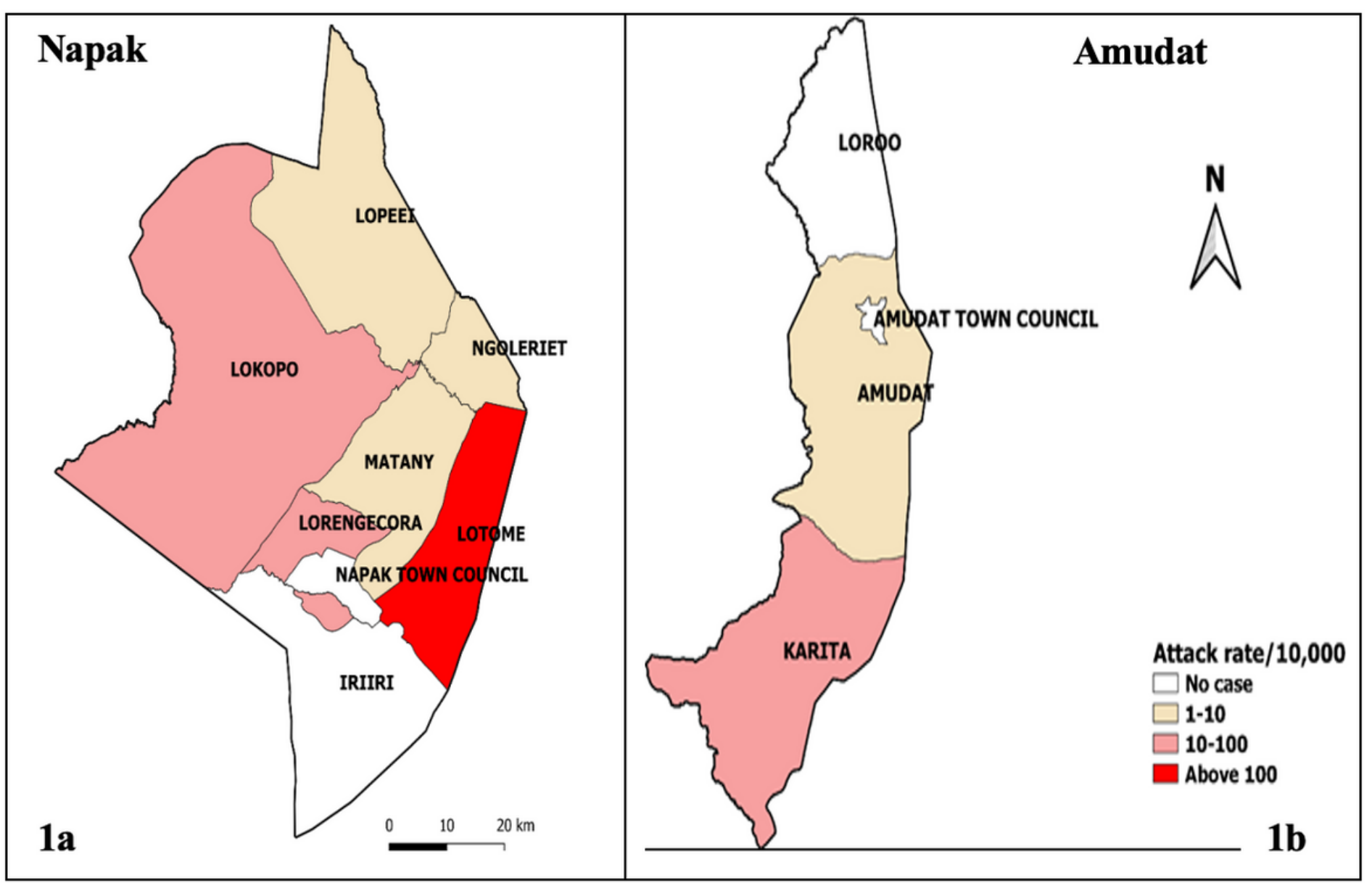

Figure 1

a \& b: Sub-county-specific attack rates during a Jimsonweed food poisoning outbreak: Napak and Amudat districts, Uganda, March-April 2019 


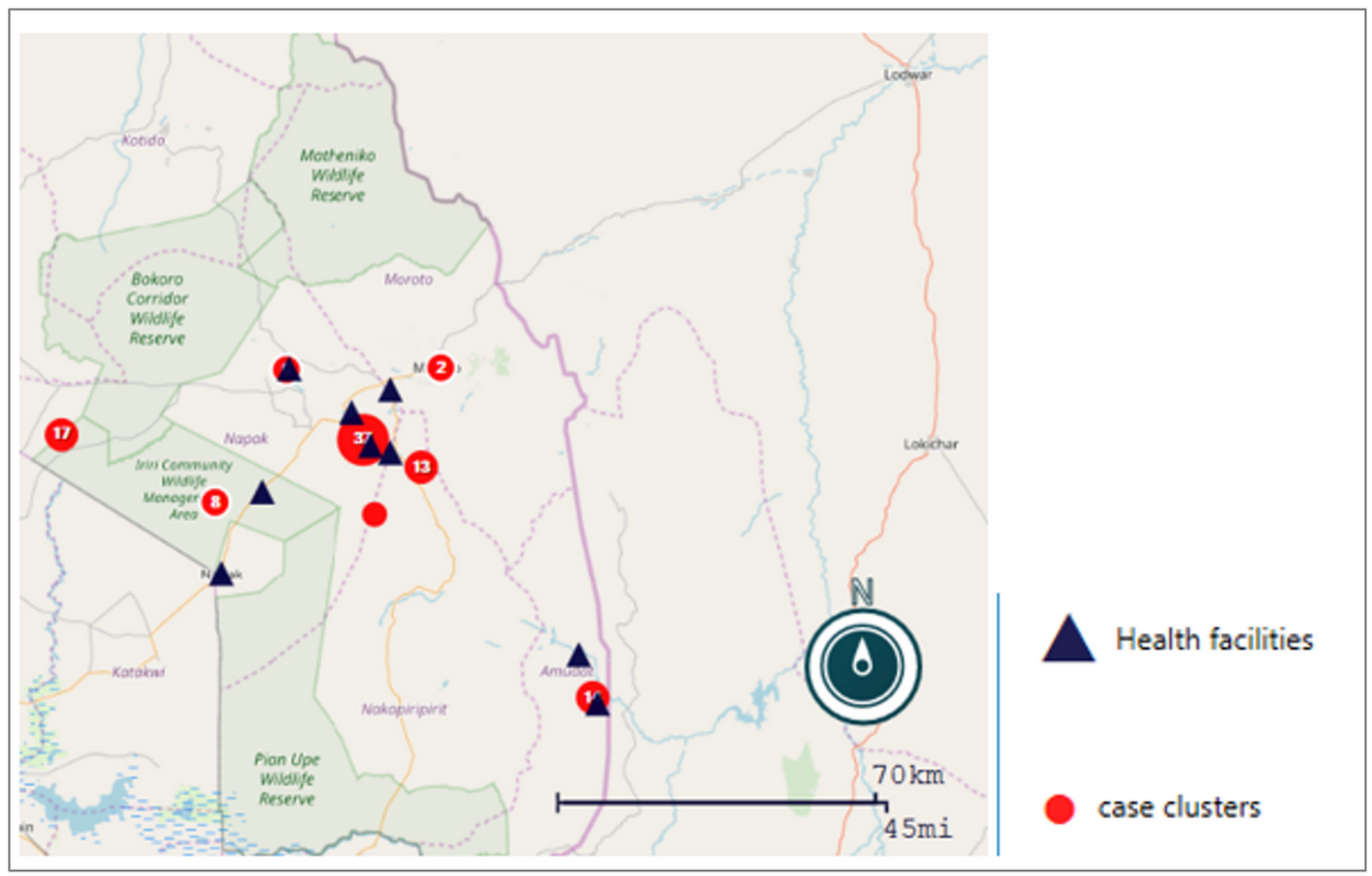

\section{Figure 2}

Proximity of cases-persons to health facilities that supplied the food during a Jimsonweed food poisoning outbreak: Napak and Amudat districts, Uganda, March-April 2019 


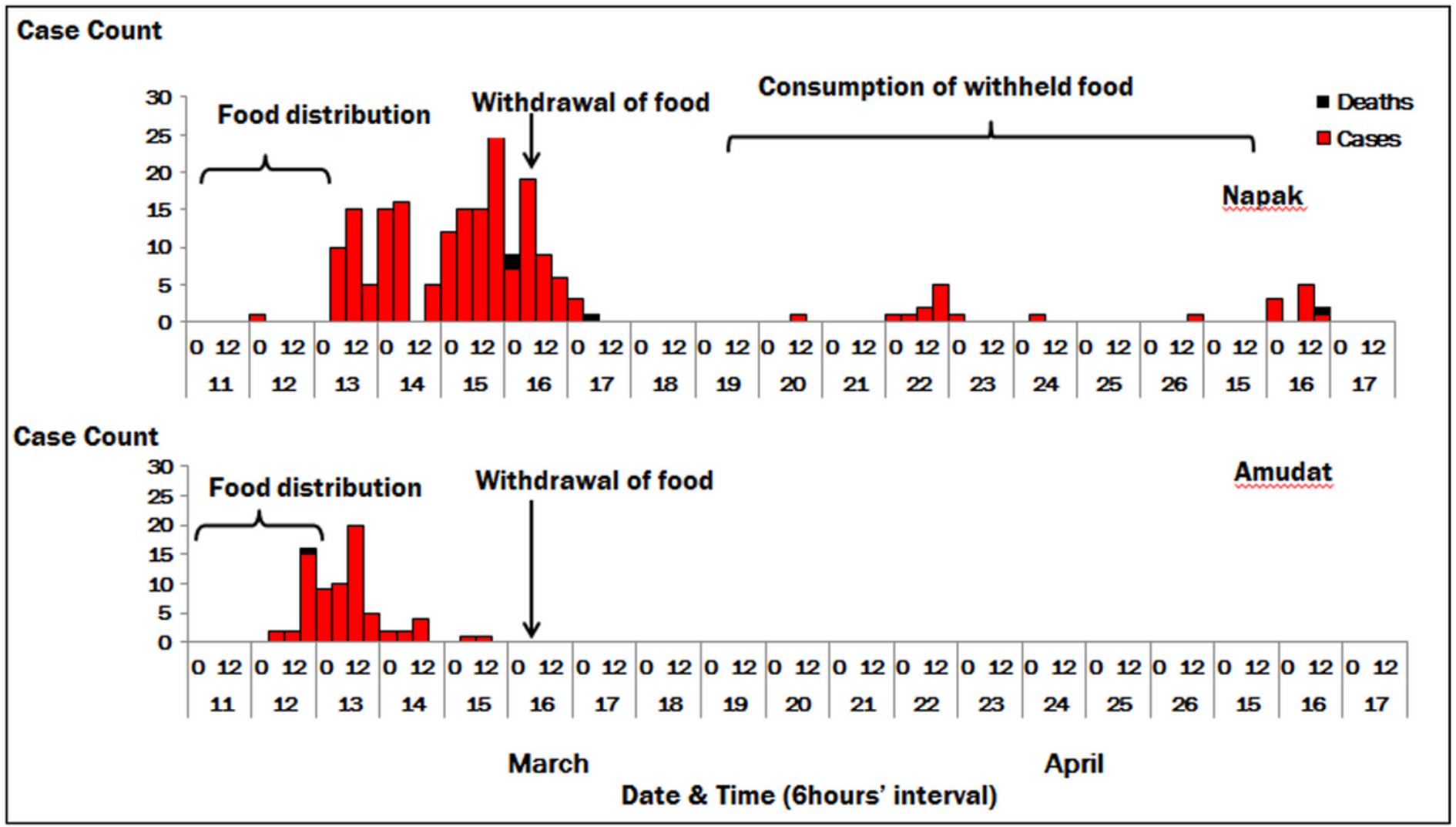

Figure 3

Onset of symptoms by 6 hour intervals during a Jimsonweed food poisoning outbreak: Amudat and Napak districts, Uganda, March-April 2019 


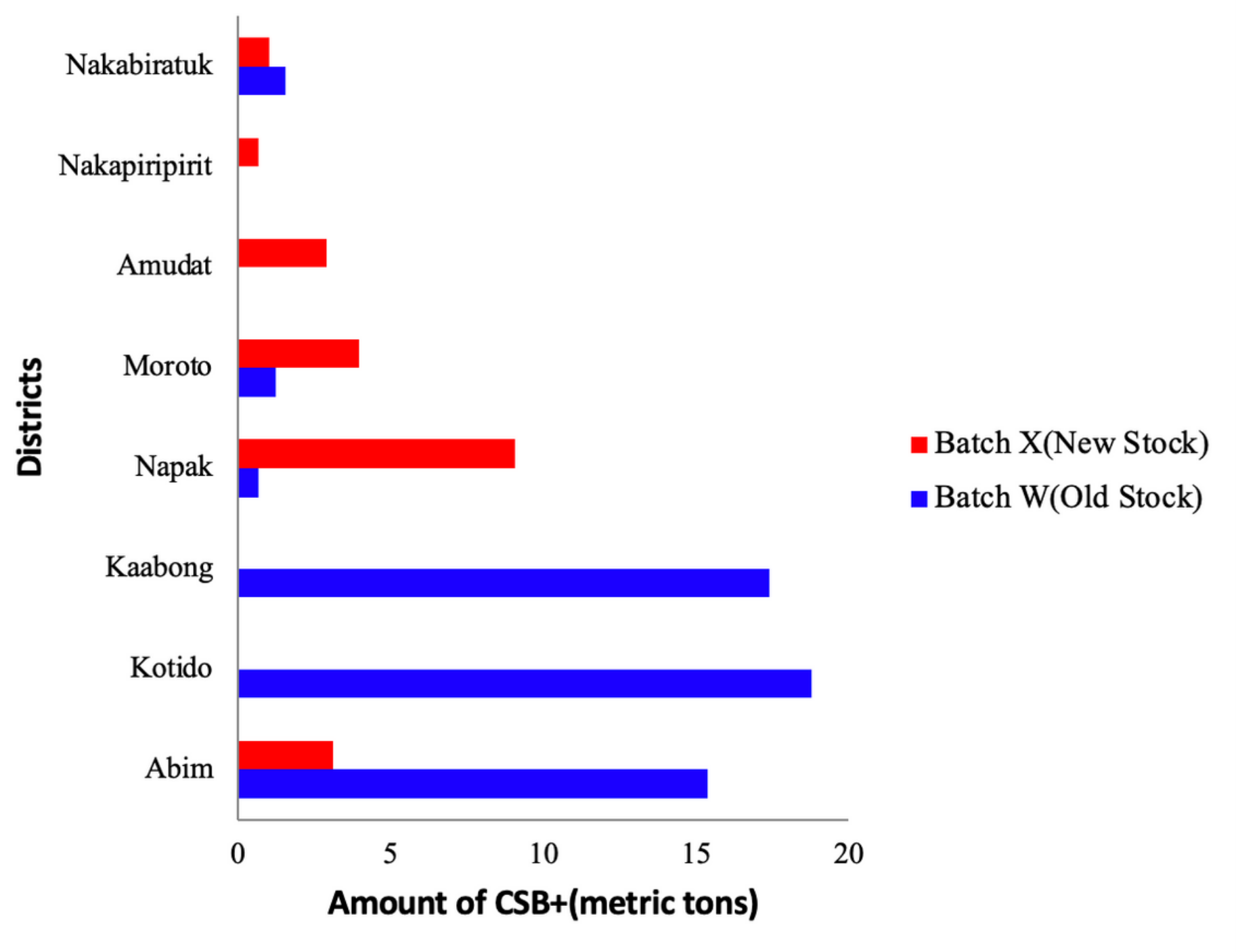

Figure 4

Volume of Batch X (implicated stock) and Batch W (old stock; not implicated in the outbreak) of Corn-Soy blend plus (CSB+) distributed to the eight districts of Karamoja region, Uganda during a Jimsonweed food poisoning outbreak, March 2019 